\title{
How Does Being Overweight Moderate Associations between Diet and Blood Pressure in Male Adolescents?
}

\author{
Jia Yap ${ }^{1}$, Hwei Min Ng ${ }^{1}$, Meredith C. Peddie ${ }^{1}\left(\mathbb{D}\right.$, Elizabeth A. Fleming ${ }^{1}{ }^{(\mathbb{D}}$, Kirsten Webster $^{1}$, Tessa Scott ${ }^{1}$ and \\ Jillian J. Haszard $2, *$ (iD \\ 1 Department of Human Nutrition, University of Otago, Dunedin 9054, New Zealand; \\ yapji273@student.otago.ac.nz (J.Y.); hwei.ng@postgrad.otago.ac.nz (H.M.N.); \\ meredith.peddie@otago.ac.nz (M.C.P.); liz.fleming@otago.ac.nz (E.A.F.); kirsten.webster@otago.ac.nz (K.W.); \\ tessa.scott@otago.ac.nz (T.S.) \\ 2 Division of Sciences, University of Otago, Dunedin 9054, New Zealand \\ * Correspondence: jill.haszard@otago.ac.nz; Tel.: +64-3-479-5683
}

Citation: Yap, J.; Ng, H.M.; Peddie, M.C.; Fleming, E.A.; Webster, K.; Scott, T.; Haszard, J.J. How Does Being Overweight Moderate Associations between Diet and Blood Pressure in Male Adolescents? Nutrients 2021, 13, 2054. https:// doi.org/10.3390/nu13062054

Academic Editor: Cristiano Fava

Received: 23 April 2021

Accepted: 10 June 2021

Published: 15 June 2021

Publisher's Note: MDPI stays neutral with regard to jurisdictional claims in published maps and institutional affiliations.

Copyright: (c) 2021 by the authors. Licensee MDPI, Basel, Switzerland. This article is an open access article distributed under the terms and conditions of the Creative Commons Attribution (CC BY) license (https:// creativecommons.org/licenses/by/ $4.0 /)$.

\begin{abstract}
Diet is one of the strongest modifiable risk factors for hypertension. In this study, we described the associations between dietary factors and blood pressure; and explored how weight status moderated these associations in a sample of New Zealand male adolescents. We collected demographics information, anthropometric, blood pressure, and dietary data from 108 male adolescents (15-17 years old). Mixed effects and logistic regression models were used to estimate relationships between dietary variables, blood pressure, and hypertension. Moderation effects of overweight status on the relationship between hypertension and diet were explored through forest plots. One-third $(36 \%)$ of the sample was classified as hypertensive. Fruit intake was related to significantly lower systolic $(-2.4 \mathrm{mmHg}, p=0.005)$ and diastolic blood pressure $(-3.9 \mathrm{mmHg}, p=0.001)$. Vegetable and milk intake was related to significantly lower diastolic blood pressure $(-1.4 \mathrm{mmHg}, p=0.047)$ and $(-2.2 \mathrm{mmHg}, p=0.003)$, respectively. In overweight participants, greater vegetable and milk, and lower meat intake appeared to reduce the odds of hypertension. Certain dietary factors may have more prominent effects on blood pressure depending on weight status.
\end{abstract}

Keywords: blood pressure; hypertension; adolescents; nutrition; obesity; New Zealand

\section{Introduction}

Non-communicable diseases, in particular cardiovascular diseases (CVD), are the primary cause of premature deaths in the world [1]. An independent risk factor for CVD is high blood pressure (BP), which contributed to $19.2 \%$ of total deaths worldwide in 2019 [2]. In New Zealand (NZ), about one in five adults (21.6\%) had high BP in 2018/19 which had remained consistent across four survey years [3]. It is well-documented that the prevalence of high BP increases steeply with age, thus, it is not surprising that NZ youth aged 15-24 years had the lowest prevalence of high BP compared to all older ages [3].

As males are more likely to develop high BP than women, understanding modifiable risk factors for men is crucial [4]. Based on the New Zealand 2018/19 Health Survey, men were 1.3 times more prone to having high BP than women (24.1\% vs. $19.2 \%)$ [3]. This difference was even more pronounced in the NZ youth population where more males $(7.9 \%)$ had high BP compared to females (3.4\%) [3]. Similar patterns were also observed in other populations around the world [5-7].

Lifestyle choices such as adherence to a healthy diet (low sodium and saturated fat intake but high fruits and vegetables intake) [6,8,9], and maintaining a healthy weight [9] at early ages lowers the risk of developing high BP in adulthood. Prospective studies have consistently demonstrated that high BP at a young age persists into later life [7] and lifestyle factors are harder to modify in adulthood [8]. Therefore, adolescence may present 
an opportune window to intervene, particularly in those who are vulnerable to developing high BP.

The key modifiable risk factor in this age group is diet $[4,8]$ but it is not known which dietary factors are associated with the greatest risk of high BP in adolescents of differing weight status. Obesity is also an important risk factor for high BP with an increasing number of studies indicating this association holds true in adolescents [6,10,11]. With just under half of the NZ youth population aged 15-24 (45.4\%) being overweight or obese [3], the risk of developing high BP in this age group is of concern. Elucidating how risk factors such as diet and body weight interact at this critical period of life can help to inform prevention strategies for early onset of hypertension, and the establishment of lifelong healthy habits.

Due to the cognisance of increasing risk for high BP among the young male population, this study first aimed to describe dietary, demographic, and body-weight risk factors associated with high BP among a sample of NZ male adolescents. Secondly, this study aimed to provide better understanding on how dietary factors are related to the risk of hypertension by overweight status, through an exploratory moderation analysis.

\section{Materials and Methods}

\subsection{Study Design}

The SuNDiAL (Survey of Nutrition, Dietary Assessment, and Lifestyle) project 2020 was a cross-sectional study conducted in high schools from five regions in NZ aiming to explore the nutritional status and lifestyle habits among male adolescents aged between 15 and 18 years. Inclusion criteria were self-identified male, 15 to 18 years of age, who could speak and understand English. The study was approved by the Human Research Ethics Committee at the University of Otago, reference number H20/004), and was registered under the Australian New Zealand Clinical Trials Registry, reference number ACTRN12620000185965.

\subsection{Recruitment}

High schools across NZ with more than 400 male students were invited to participate via email. The SuNDiAL research teams visited participating schools and advertised the study to students through presentations and printed information. Interested students provided an email address and were sent a link to complete online consent and enrolment. Additional parental consent was required from students aged under 16 years. Recruitment was initially scheduled in two phases; February-April and July-September 2020; however, this was halted on the 23 of March 2020 due to coronavirus (COVID-19) lockdown.

\subsection{Data Collection}

Data were collected in three ways: a self-administered online questionnaire; an inschool visit; and a follow-up phone- or video-call. The online questionnaire, administered through Research Electronic Data Capture (REDCap) (Vanderbilt University), included demographic and health questions, as well as questionnaires about dietary habits, attitudes, and motivations for food choice. The in-school visit included a 24-h diet recall, anthropometric assessment, and BP measurement. The follow-up phone- or video-call was undertaken to collect a second 24-h diet recall.

\subsection{Demographics}

Upon completing online consent, participants provided demographic information. This included home address and ethnicity. Socioeconomic status was measured based on New Zealand Deprivation Index 2018 deciles according to their home address, with 1 indicating the least deprived areas and 10 being the most deprived areas [12]. This was further categorized into low deprivation (score 1-3), moderate deprivation (score 4-7) and high deprivation (score 8-10). Self-identified ethnicity was assessed using the 2006 NZ census ethnicity questions and were prioritised into four ethnic groups based on the 
Ministry of Health's priority classification system: Māori, followed by Pacific, then Asian, and finally New Zealand European and others [13].

\subsection{Dietary Habits and Intake}

Dietary habits were assessed with the Dietary Habits Questionnaire [14]. This asked, on average, how often the participant consumed various food groups (fruit, vegetables, milk, meat, plant protein, sweet drinks, and snacks), with 10 response options ranging from 'never' to 'more than three times a day'. Some food groups were combined from smaller categories: 'Meat' was a combination of questions on red meat, pork, poultry, fish, seafood, and processed meat; 'Plant protein' was generated from questions about legumes, tofu, and vegetarian meat alternatives consumption; and 'Snacks' was a combination of questions about sweets and chocolate, sweet snacks (like biscuits and muesli bars), and savoury snacks (like crisps and crackers). Ordinal responses were first converted to average 'times per day' before combining foods together.

Dietary intake was assessed using two 24-h diet recalls performed on two nonconsecutive days (preferably one weekday and one weekend day) a week apart. The first recall involved a physical interview at one of the school visits (or via phone/video call during COVID-19 lockdown for one school, $n=24$ participants). The second recall was conducted via phone/video call. These were carried out according to a four-pass method as described elsewhere [15]. In brief, the participant and interviewer generated a quick list of all food and drinks consumed the previous day, followed by a detailed description of each food and beverage including brand, amount, and time consumed. Lastly, the interviewer and participant checked through the generated list together. Supermarket webpages were used to assist participants with reporting brands. Household measures and a photo booklet were used to help participants estimate portion sizes. Dietary intakes were entered into FoodWorks software (FOODfiles 2016-Version 01) for nutrient analysis and the multiple source method was applied to adjust for intra-individual variability [16]. Energy, fat, protein, carbohydrate, and fibre intake were adjusted to represent usual daily intakes. As energy intake varied considerably, fat, protein, and carbohydrate intake were converted to percent of energy intake using Atwater factors.

\subsection{Anthropometry}

Anthropometric measures were taken by trained SuNDiAL research teams using standard protocols [17]. Height and weight were collected in duplicate and a third measurement was taken if there was a 0.5 difference between the two initial measurements. Participants were required to remove shoes and heavy clothing before any measurements were carried out. Standing height was measured to the nearest $0.1 \mathrm{~cm}$ using a portable stadiometer (Seca 213 (Seca, Hamburg, Germany) or Wedderburn (Wedderburn, Sydney, Australia) stadiometer). Weight was recorded using the one of Medisana PS420 (Medisana, Nuess, Germany); Salter 9037 BK3R (Salter, Kent, United Kingdom); Seca Alpha 770 (Seca, Hambury, Germany); or Soehnle Style Sense Comfort 400 (Soehnle, Backnang, Germany) scales and recorded to the nearest $0.1 \mathrm{~kg}$. Body Mass Index (BMI) was calculated as weight $(\mathrm{kg})$ divided by height squared $\left(\mathrm{m}^{2}\right)$. The BMI-for-age $z$-score was calculated with World Health Organisation growth reference data and was used to interpret weight status [18]. A BMI $z$-score of $>+1$ to $\leq+2$ was classified as overweight and $>+2$ as obese [18].

\subsection{Blood Pressure}

BP was measured using a digital blood pressure monitor (OMRON HEM-907; Omron Healthcare, Kyoto, Japan). Prior to having their measurements taken, participants were required to be in a seated position for $15 \mathrm{~min}$, using an appropriately sized cuff with the artery indicator at the correct anatomical position. The BP monitor was set to take three measurements at one-minute intervals, and the average was recorded. The American Academy of Pediatrics cut off values were used to define elevated BP $(\geq 120 \mathrm{mmHg}$ systolic and $<80 \mathrm{mmHg}$ diastolic), and hypertension $(>130 / 80 \mathrm{mmHg}$ ) [19]. 


\subsection{Statistical Analysis}

All statistical analysis was carried out using Stata 16.1 (StataCorp, College Station, TX, USA). As some participants with BP measurements did not complete a diet recall and/or the dietary habits questionnaire, demographic, and anthropometric differences between those with and without this data were assessed with $\mathrm{t}$-tests for continuous variables (age and BMI $z$-score) and Fisher's exact tests for categorical variables (deprivation, ethnicity, and weight status).

Mixed effects regression models were used to estimate the relationship between dietary variables and systolic and diastolic BP. BP was the dependent variable, dietary intake was the independent variable, and school was included as a random effect. Adjusted models were also generated that adjusted for age, ethnicity, and BMI $z$-score. Residuals of the models were plotted and visually assessed for heteroskedasticity and normality. The odds of hypertension associated with the demographic and dietary variables were estimated using logistic regression models with a sandwich estimator for school clusters. Adjusted estimates were also calculated controlling for age and BMI $z$-score.

To assess the moderating effect of overweight status on the relationships between diet and hypertension, forest plots were generated to illustrate the odds ratio (OR) and $95 \%$ confidence interval (CI) by whether participants were classified as overweight or not. Overweight participants were those who were classified as either overweight or obese. Testing for moderating effects involves the inclusion of an interaction term in the model, between the moderating variable and the independent variable. However, our sample size was too small to have the power to detect 'statistically significant' interactions for meaningful moderations (thus inflating the possibility of Type II error). Therefore, statistical tests of interaction were not carried out. Instead, the forest plots illustrate the possibility of clinically important moderation by examining if the odds ratios were markedly different between groups. If the estimates for each group are not dissimilar, then meaningful moderation is unlikely, regardless of sample size [20,21].

\section{Results}

Six high schools took part in the SuNDiAL 2020 study. A total of 146 students consented to the study but only 108 students attended an in-school visit and had their BP taken. Among these, 104 (96\%) completed health and demographic questionnaire, $97(90 \%)$ completed dietary habits questionnaire, and $88(81 \%)$ completed at least one 24 -h diet recall. Those who completed the dietary habits questionnaire $(n=97)$ were not noticeably different from the whole sample $(n=108)$ in terms of the demographics reported in Table 1 (all $p>0.1$, analysis not shown). Similarly, in those who completed diet recalls $(n=88)$ there was no evidence of demographic differences from the whole sample (all $p>0.1$, analysis not shown).

Table 1. Demographic characteristics, weight status, and blood pressure $(n=108)$.

\begin{tabular}{|c|c|c|}
\hline Variable & $N(\%)^{a}$ & Range \\
\hline Age, mean (SD) years & $16.6(0.7)$ & 15.0 to 17.9 \\
\hline Deprivation $b$, mean (SD) & $4.9(2.6)$ & 1 to 10 \\
\hline Low & $34(32.7)$ & \\
\hline Medium & $47(45.2)$ & \\
\hline High & $23(22.1)$ & \\
\hline Ethnicity & & 104 participants responded to this question \\
\hline Māori & $10(9.6)$ & \\
\hline Pacific & $3(2.9)$ & \\
\hline Asian & $35(33.7)$ & \\
\hline $\mathrm{NZEO}^{\mathrm{c}}$ & $56(53.9)$ & \\
\hline BMI $z$-score ${ }^{\mathrm{d}}$, mean (SD) & $0.45(1.10)$ & -1.88 to 3.42 \\
\hline Weight status $\mathrm{d}$ & & \\
\hline Healthy weight & $72(66.7)$ & \\
\hline
\end{tabular}


Table 1. Cont.

\begin{tabular}{|c|c|c|}
\hline Variable & $N(\%)^{a}$ & Range \\
\hline Overweight & $30(27.8)$ & \\
\hline Obese & $6(5.6)$ & \\
\hline $\begin{array}{l}\text { Systolic blood pressure, mean } \\
\text { (SD) } \mathrm{mmHg}\end{array}$ & $124(12)$ & 88 to 154 \\
\hline $\begin{array}{c}\text { Diastolic blood pressure, } \\
\text { mean (SD) } \mathrm{mmHg}\end{array}$ & $65(9)$ & 45 to 89 \\
\hline Elevated blood pressure ${ }^{\mathrm{e}}$ & $63(58.3)$ & \\
\hline Hypertensive $^{\mathrm{e}}$ & $40(37.0)$ & \\
\hline \multicolumn{3}{|c|}{  } \\
\hline
\end{tabular}

Demographics, weight status and BP are described in Table 1. Mean systolic BP (SD) was $124 \mathrm{mmHg}$ (12.0) while diastolic BP (SD) was $65 \mathrm{mmHg}$ (9.0). Just over half of participants were classified as having high $\mathrm{BP}(n=63,58.3 \%)$, while over one-third ( $n=40$, $37.9 \%$ ) were classified as hypertensive.

Table 2 shows the mean difference and $95 \% \mathrm{CI}$ in systolic and diastolic BP for dietary habits and intake. After adjusting for age, ethnicity, and BMI $z$-score, each serve of fruit per day was associated with $2.4 \mathrm{mmHg}$ lower systolic ( $95 \% \mathrm{CI}-4.0,-0.7)$ and $2.5 \mathrm{mmHg}$ lower diastolic BP $(95 \% \mathrm{CI}-3.9,-1.1)$. Similarly, vegetable and milk were associated with a $1.4 \mathrm{mmHg}(95 \% \mathrm{CI}-1.8,-0.4)$ and $2.2 \mathrm{mmHg}(95 \% \mathrm{CI}-3.6,-0.8)$ lower diastolic $\mathrm{BP}$, respectively.

Table 2. Dietary habits and intake related to systolic and diastolic blood pressure.

\begin{tabular}{|c|c|c|c|c|c|c|}
\hline & $n$ & Mean (SD) & $\begin{array}{l}\text { Mean Difference } \\
(95 \% \mathrm{CI})^{\mathrm{a}}, \mathrm{mmHg}\end{array}$ & $p$-Value & $\begin{array}{c}\text { Adjusted Mean } \\
\text { Difference }(95 \% \mathrm{CI})^{\mathrm{a}} \\
\mathrm{mmHg}\end{array}$ & $p$-Value \\
\hline \multicolumn{7}{|c|}{ Systolic blood pressure } \\
\hline \multicolumn{7}{|c|}{ Dietary habits ${ }^{b}$, serves per day } \\
\hline Fruit & 97 & $1.4(1.1)$ & $-2.2(-4.3,-0.1)$ & 0.040 & $-2.4(-4.0,-0.7)$ & 0.005 \\
\hline Vegetables & 97 & $1.6(1.2)$ & $0.1(-1.9,2.1)$ & 0.935 & $-0.7(-2.4,0.9)$ & 0.370 \\
\hline Milk & 97 & $1.3(1.1)$ & $-0.6(-2.8,1.6)$ & 0.573 & $-0.7(-2.5,1.0)$ & 0.410 \\
\hline Meat & 96 & $2.2(1.2)$ & $-0.4(-2.4,1.6)$ & 0.702 & $-1.3(-2.9,0.3)$ & 0.110 \\
\hline Plant protein ${ }^{c}$ & 96 & $1.5(1.3)$ & $0.8(-0.9,2.6)$ & 0.352 & $0.7(-0.7,2.1)$ & 0.352 \\
\hline Sweet drinks d & 97 & $1.1(1.6)$ & $0.4(-1.0,1.9)$ & 0.574 & $0.4(-0.9,1.7)$ & 0.519 \\
\hline Snacks $\mathrm{e}^{\mathrm{C}}$ & 97 & $2.0(1.8)$ & $-1.3(-2.5,-0.04)$ & 0.043 & $-0.3(-1.4,0.7)$ & 0.532 \\
\hline \multicolumn{7}{|l|}{ Daily dietary intake ${ }^{f}$} \\
\hline Energy, MJ & 88 & $10.7(3.9)$ & $-0.2(-0.9,0.5)$ & 0.627 & $-0.1(-0.7,0.5)$ & 0.693 \\
\hline Protein, $\%$ energy & 88 & $18.3(3.2)$ & $0.1(-0.7,1.0)$ & 0.736 & $-0.2(-0.9,0.5)$ & 0.517 \\
\hline Fat, \% energy & 88 & $37.6(6.0)$ & $0.0(-0.4,0.4)$ & 0.998 & $-0.1(-0.5,0.3)$ & 0.562 \\
\hline Carbohydrate, $\%$ energy & 88 & $45.6(6.8)$ & $-0.2(-0.6,0.2)$ & 0.393 & $0.1(-0.3,0.4)$ & 0.685 \\
\hline Fibre, $\mathrm{g}$ & 88 & $25.8(11.2)$ & $-0.1(-0.3,0.2)$ & 0.506 & $-0.2(-0.5,0.2)$ & 0.308 \\
\hline \multicolumn{7}{|c|}{ Diastolic blood pressure } \\
\hline \multicolumn{7}{|l|}{ Dietary habits ${ }^{b}$, serves per day } \\
\hline Fruit & 97 & $1.4(1.1)$ & $-2.5(-4.0,-0.9)$ & 0.002 & $-2.5(-3.9,-1.1)$ & 0.001 \\
\hline Vegetables & 97 & $1.6(1.2)$ & $-1.1(-2.6,0.5)$ & 0.174 & $-1.4(-2.8,-0.02)$ & 0.047 \\
\hline Milk & 97 & $1.3(1.1)$ & $-2.2(-3.9,-0.6)$ & 0.007 & $-2.2(-3.6,-0.8)$ & 0.003 \\
\hline Meat & 96 & $2.2(1.2)$ & $-0.4(-1.9,1.2)$ & 0.629 & $-1.2(-2.6,0.2)$ & 0.083 \\
\hline Plant protein ${ }^{\mathrm{c}}$ & 96 & $1.5(1.3)$ & $1.4(0.01,2.7)$ & 0.048 & $1.1(-0.04,2.3)$ & 0.058 \\
\hline Sweet drinks ${ }^{d}$ & 97 & $1.1(1.6)$ & $0.3(-0.8,1.5)$ & 0.567 & $0.2(-0.9,1.3)$ & 0.701 \\
\hline
\end{tabular}


Table 2. Cont.

\begin{tabular}{|c|c|c|c|c|c|c|}
\hline & $n$ & Mean (SD) & $\begin{array}{l}\text { Mean Difference } \\
(95 \% \mathrm{CI})^{a}, \mathrm{mmHg}\end{array}$ & $p$-Value & $\begin{array}{c}\text { Adjusted Mean } \\
\text { Difference }(95 \% \mathrm{CI}){ }^{a}, \\
\text { mmHg }\end{array}$ & $p$-Value \\
\hline \multicolumn{7}{|c|}{ Diastolic blood pressure } \\
\hline Snacks e & 97 & $2.0(1.8)$ & $-0.9(-1.9,0.1)$ & 0.066 & $-0.3(-1.2,0.6)$ & 0.549 \\
\hline \multicolumn{7}{|l|}{ Daily dietary intake ${ }^{\mathrm{f}}$} \\
\hline Energy, MJ & 88 & $10.7(3.9)$ & $-0.4(-1.0,0.1)$ & 0.102 & $-0.5(-1.0,-0.04)$ & 0.034 \\
\hline Protein, $\%$ energy & 88 & $18.3(3.2)$ & $0.4(-0.2,1.0)$ & 0.210 & $0.2(-0.3,0.8)$ & 0.378 \\
\hline Fat, \% energy & 88 & $37.6(6.0)$ & $0.1(-0.2,0.5)$ & 0.412 & $0.1(-0.2,0.4)$ & 0.439 \\
\hline Carbohydrate, $\%$ energy & 88 & $45.6(6.8)$ & $-0.3(-0.6,0.02)$ & 0.065 & $-0.2(-0.5,0.1)$ & 0.144 \\
\hline Fibre, $g$ & 88 & $25.8(11.2)$ & $-0.2(-0.4,-0.01)$ & 0.037 & $-0.2(-0.5,0.0)$ & 0.074 \\
\hline
\end{tabular}

a Mean differences (95\% CI) estimated using a mixed effects regression model, with school as a random effect. Adjusted estimates were adjusted for age, ethnicity, and BMI $z$-score. Fibre intake was also adjusted for energy intake; ${ }^{b}$ Dietary habits assessed using the dietary habits questionnaire and measures frequency of intake; ${ }^{c}$ Plant protein includes legumes, chickpeas, kidney beans, baked beans, tofu, tempeh, tofu products, vegetarian ingredients (such as Quorn, nut meat, vegetarian mince), vegetarian sausages, nuggets, patties, vegetarian "meat alternatives" (such as chicken-free chicken, vegetarian chicken schnitzel, meat-free bacon rashers); ${ }^{\mathrm{d}}$ Sweet drinks includes "diet" drinks but excludes alcoholic beverages (sensitivity analysis looking at diet sweet drinks separately saw a small change but did not influence estimates markedly: adjusted mean difference $(95 \% \mathrm{CI})$ : systolic $1.2(-3.4,5.8) \mathrm{mmHg}, p=0.611 ;$ diastolic $0.5(-3.5,4.5)$ mmHg, $p=0.802) ;{ }^{e}$ Snacks includes lollies, sweets, chocolate, confectionary, biscuits, cakes, muffins, sweet pastries, muesli or nut bars, and savoury snacks such as crisps and crackers; ${ }^{\mathrm{f}} \mathrm{MJ}$ : Megajoules; Dietary intake assessed using 24-h recalls, adjusted for usual intake. Three participants are missing ethnicity data and are not included in the adjusted estimates.

Demographic and dietary predictors of hypertension are presented in Table 3. The odds of hypertension increased by $3.16(95 \%$ CI $2.39,4.19)$ for each additional year of age. Overweight individuals were 9.4 times (95\% CI 2.89, 30.69) more likely to have hypertension than normal weight individuals. There were no significant associations between dietary intakes or habits and adjusted odds of hypertension.

Table 3. Demographic and dietary habits and the odds of hypertension $(n=97)$.

\begin{tabular}{|c|c|c|c|c|c|c|}
\hline & $\begin{array}{c}\text { Not } \\
\text { Hypertensive } \\
(n=62)\end{array}$ & $\begin{array}{l}\text { Hypertensive } \\
\quad(n=35)\end{array}$ & $\begin{array}{l}\text { Odds Ratio } \\
(95 \% \mathrm{CI})^{a}\end{array}$ & $p$-Value & $\begin{array}{l}\text { Adjusted Odds } \\
\text { Ratio }\left(95 \% \text { CI) }^{\text {a }}\right.\end{array}$ & $p$-Value \\
\hline Age, years & $16.5(0.7)$ & $16.9(0.6)$ & $2.62(1.72,3.99)$ & $<0.001$ & $3.16(2.39,4.19)$ & $<0.001$ \\
\hline \multicolumn{7}{|l|}{ Age group, $n(\%)$} \\
\hline 15 to $<17$ years & $48(72.7)$ & $18(27.3)$ & Reference & & Reference & \\
\hline 17 to $<18$ years & $14(45.2)$ & $17(54.8)$ & $3.24(1.62,6.47)$ & 0.001 & $3.54(1.61,7.84)$ & 0.002 \\
\hline \multicolumn{7}{|l|}{ Deprivation, $n(\%)$} \\
\hline Low & $24(72.7)$ & $9(27.3)$ & Reference & & Reference & \\
\hline Medium & $27(62.8)$ & $16(37.2)$ & $1.58(0.38,6.54)$ & 0.528 & $1.28(0.41,4.04)$ & 0.670 \\
\hline High & $11(52.4)$ & $10(47.6)$ & $2.42(0.54,10.83)$ & 0.246 & $0.94(0.32,2.74)$ & 0.914 \\
\hline \multicolumn{7}{|l|}{ Ethnicity, $n(\%)$} \\
\hline NZEO & $36(64.3)$ & $20(35.7)$ & Reference & & Reference & \\
\hline Māori & $6(60.0)$ & $4(40.0)$ & $1.20(0.28,5.12)$ & 0.806 & $1.21(0.45,3.27)$ & 0.701 \\
\hline Asian & $20(64.5)$ & $11(35.5)$ & $0.99(0.46,2.15)$ & 0.980 & $2.05(0.98,4.29)$ & 0.058 \\
\hline BMI z-score, mean (SD) & $0.04(0.99)$ & $1.15(1.03)$ & $3.01(1.03,8.76)$ & 0.044 & $3.24(1.08,9.69)$ & 0.036 \\
\hline \multicolumn{7}{|l|}{ Weight status, $n(\%)$} \\
\hline Not overweight & $51(79.7)$ & $13(20.3)$ & Reference & & Reference & \\
\hline Overweight & $11(33.3)$ & $22(66.7)$ & $7.85(2.54,24.16)$ & $<0.001$ & $9.42(2.89,30.69)$ & $<0.001$ \\
\hline \multicolumn{7}{|l|}{$\begin{array}{l}\text { Dietary habits }{ }^{b} \text {, median } \\
\text { (25th, } 75 \text { th percentiles) } \\
\text { serves per day }\end{array}$} \\
\hline Fruit & $1(0.4,2)$ & $1(0.4,2)$ & $0.84(0.54,1.28)$ & 0.410 & $0.69(0.40,1.19)$ & 0.183 \\
\hline Vegetables & $1(0.8,2)$ & $1(0.8,2)$ & $1.03(0.76,1.39)$ & 0.858 & $0.84(0.59,1.18)$ & 0.316 \\
\hline Milk & $1(0.4,2.5)$ & $1(0.4,2.5)$ & $1.14(0.78,1.67)$ & 0.497 & $1.12(0.67,1.87)$ & 0.663 \\
\hline Meat & $1.8(1.4,2.7)$ & $2.0(1.5,2.6)$ & $1.11(0.92,1.34)$ & 0.256 & $0.96(0.64,1.46)$ & 0.862 \\
\hline Plant protein ${ }^{c}$ & $0.8(0.4,2.5)$ & $0.7(0.2,3.5)$ & $1.05(0.88,1.25)$ & 0.583 & $1.03(0.66,1.60)$ & 0.901 \\
\hline Sweet drinks $d$ & $0.6(0.1,1.2)$ & $0.8(0.1,1.3)$ & $1.13(1.03,1.24)$ & 0.008 & $1.16(0.998,1.34)$ & 0.053 \\
\hline
\end{tabular}


Table 3. Cont.

\begin{tabular}{|c|c|c|c|c|c|c|}
\hline & $\begin{array}{c}\text { Not } \\
\text { Hypertensive } \\
(n=62)\end{array}$ & $\begin{array}{l}\text { Hypertensive } \\
\quad(n=35)\end{array}$ & $\begin{array}{l}\text { Odds Ratio } \\
(95 \% \text { CI })^{a}\end{array}$ & $p$-Value & $\begin{array}{l}\text { Adjusted Odds } \\
\text { Ratio }\left(95 \% \text { CI) }^{a}\right.\end{array}$ & $p$-Value \\
\hline Snacks ${ }^{\mathrm{e}}$ & $1.6(0.8,2.6)$ & $1.3(0.6,2.1)$ & $0.94(0.81,1.09)$ & 0.399 & $1.09(0.83,1.42)$ & 0.548 \\
\hline Daily dietary intake ${ }^{f}$ & $N=55$ & $N=33$ & & & & \\
\hline Energy, MJ & $11.0(4.3)$ & $10.3(3.2)$ & $0.95(0.89,1.01)$ & 0.078 & $0.88(0.74,1.05)$ & 0.164 \\
\hline Protein, $\%$ energy & $18.3(3.3)$ & $18.2(3.0)$ & $0.99(0.85,1.15)$ & 0.893 & $0.94(0.79,1.12)$ & 0.491 \\
\hline Fat, \% energy & $32.3(6.2)$ & $38.0(5.8)$ & $1.02(0.96,1.09)$ & 0.534 & $1.04(0.96,1.12)$ & 0.340 \\
\hline Carbohydrate, \% energy & $46.0(6.1)$ & $44.9(8.0)$ & $0.98(0.94,1.01)$ & 0.199 & $1.00(0.93,1.06)$ & 0.884 \\
\hline Fibre, $\mathrm{g}$ & $27.1(11.6)$ & $23.6(10.3)$ & $0.97(0.94,0.997)$ & 0.033 & $0.93(0.85,1.02)$ & 0.117 \\
\hline
\end{tabular}

${ }^{\text {a }}$ Odds ratios $(95 \% \mathrm{CI})$ estimated using a logistics regression model, accounting for school with a sandwich estimator. Adjusted estimates were adjusted for age and BMI $z$-score. Fibre intake was also adjusted for energy intake; ${ }^{b}$ Dietary habits assessed using the dietary habits questionnaire and measures frequency of intake; ${ }^{c}$ Plant protein includes legumes, chickpeas, kidney beans, baked beans, tofu, tempeh, tofu products, vegetarian ingredients (such as Quorn, nut meat, vegetarian mince), vegetarian sausages, nuggets, patties, vegetarian "meat alternatives" (such as chicken-free chicken, vegetarian chicken schnitzel, meat-free bacon rashers); d Sweet drinks includes "diet" drinks but excludes alcoholic beverages (sensitivity analysis showed a significantly lower odds for each non-diet drink extra per day: adjusted

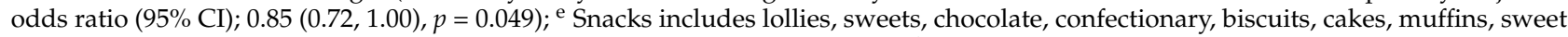
pastries, muesli or nut bars, and savoury snacks such as crisps and crackers; ${ }^{\mathrm{f}}$ Dietary intake assessed using 24 -h recalls, adjusted for usual intake.

Weight status appeared to moderate some relationships between diet and hypertension (Figure 1). Vegetable and milk consumption were more protective against the odds of hypertension in overweight adolescents (OR 0.64 (95\% CI 0.40, 1.02) and OR $0.82(95 \%$ CI $0.56,1.19)$ ) than in those who had normal weight. Meat consumption in overweight participants was non-significantly related to increased odds of hypertension by 1.34 times, but lower odds of hypertension among normal weight adolescents. Note that overweight adolescents had similar vegetable, milk, and meat intakes as their normal weight counterparts (Table A1 Appendix A). The relationship between macronutrient composition of the diet and hypertension did not appear to be moderated by weight status (Figure 2).

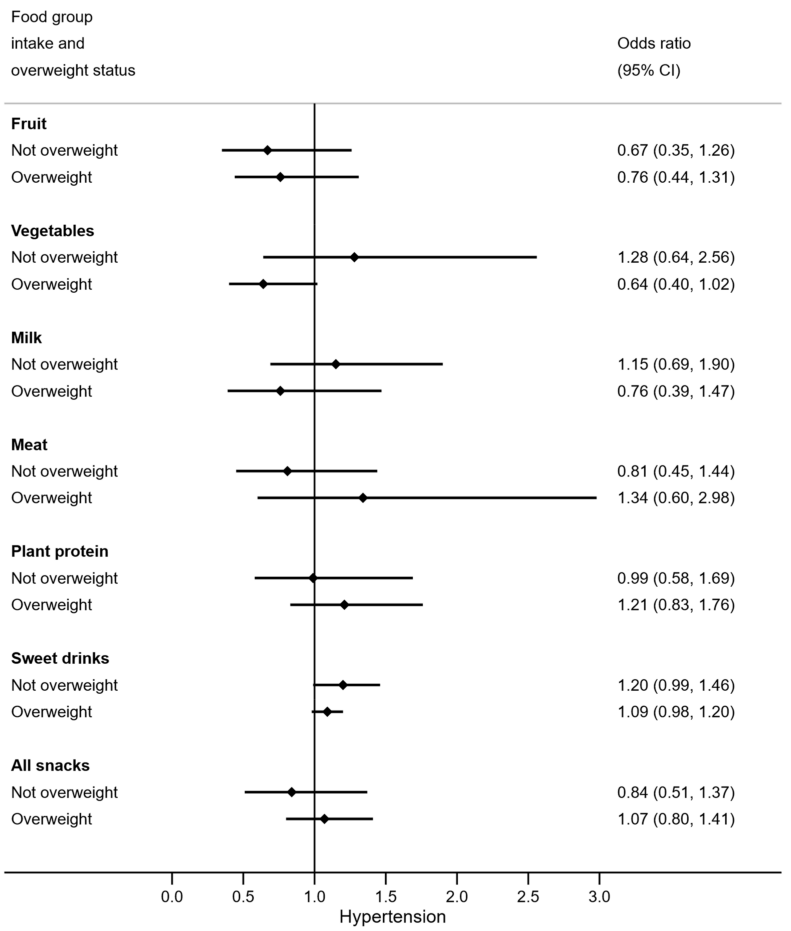

Figure 1. Odds of hypertension for each serve per day of various food groups, by overweight status. $N=97$ ( $n=33$ overweight). Odds ratios are adjusted for age. 


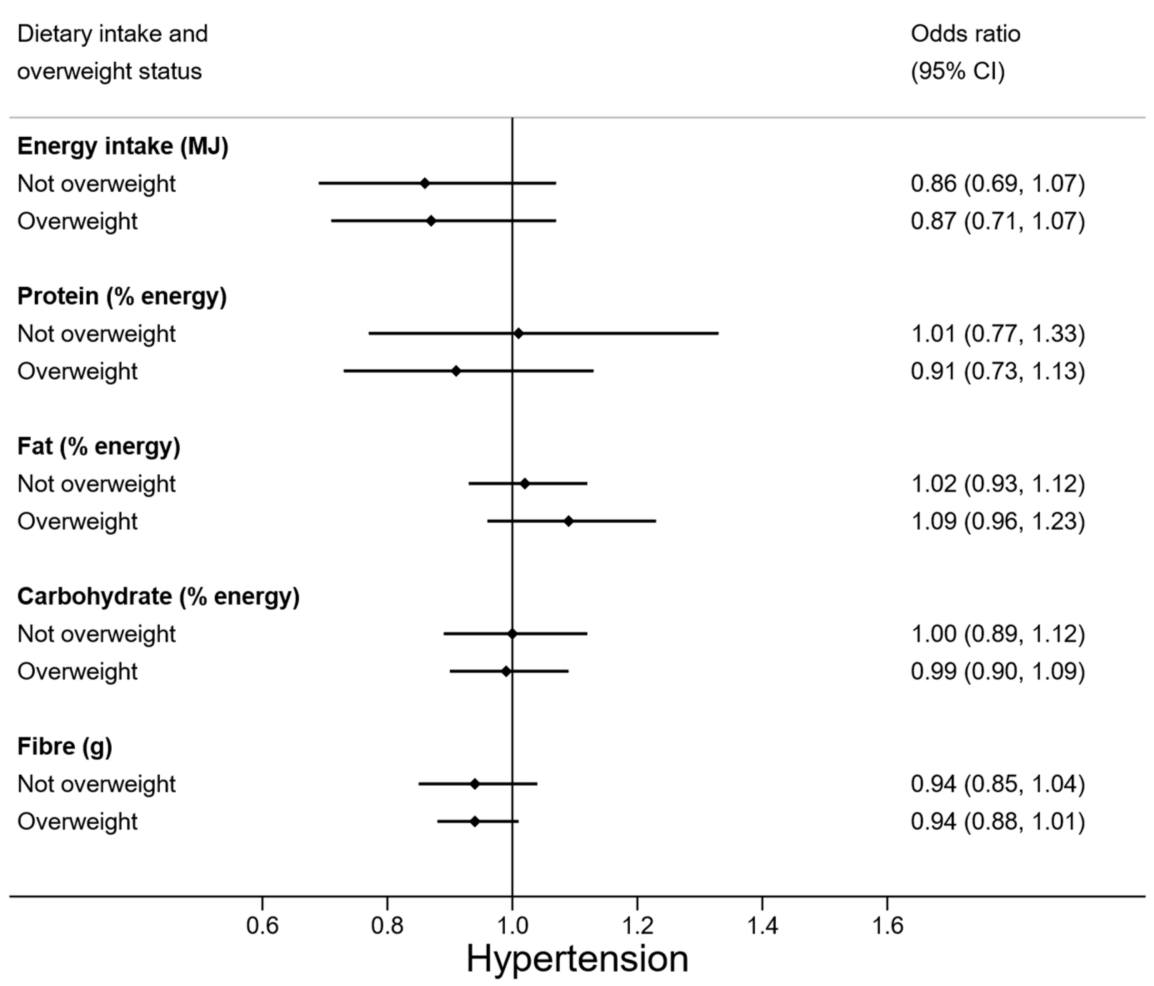

Figure 2. Odds of hypertension for energy, macronutrient, and fibre intake, by overweight status. $N=88$ ( $n=30$ overweight). Odds ratios are adjusted for age.

\section{Discussion}

High BP is a silent health problem that may go unnoticed in adolescents as they are not routinely measured. Among our sample of 15-to-17-year-old NZ male adolescents, more than half had high BP, with more than a third classified as hypertensive. Age and weight status were the strongest predictors of hypertension while fruit, vegetable, and milk intake, were shown to be associated with a lower BP. Exploratory analysis results indicated that weight status may moderate associations between diet and hypertension. Among overweight individuals, more servings of vegetables and milk, and a lower number of servings of meat a day appeared to be associated with decreased odds of hypertension, but not in normal weight adolescents.

Our results extend previous observations on the hypotensive effects of fruit and vegetable intake in adolescents and adults [22-25]. The exact mechanism of how this food group lowers BP is unclear; however, their high potassium and antioxidant contents are suggested to exert cardio protective effects via vasodilation $[9,26]$. Apart from this, they are also rich in fibre which has consistently demonstrated BP-lowering properties in prior studies [26-29]. The benefits of fibre intake on BP were somewhat supported by the current results. Likewise, the positive effects of milk intake on BP have also been observed in earlier research $[30,31]$. Evidence suggests that phosphorus, calcium, and magnesium (all found in dairy products) can exhibit BP lowering properties through the maintenance of cellular structure and function, which regulates the vascular tone [31].

While not statistically significant, our findings also support a relationship between sweet drink intake and BP as reported by earlier literature [32-34]. Note that previous studies only investigated the effects of sugar sweetened beverages on BP whereas ours included artificially sweetened beverages (diet drinks). Interestingly, despite the absence of fructose that was suggested to induce hypertension in sugar sweetened beverages [34], hypertensive adolescents reported higher diet drink consumption compared to their normotensive counterparts (mean intake $=1.9$ per week compared to 0.6 per week). This was also reported in another study where diet drink consumers had higher BP than sugar sweetened beverage consumers and non-consumers $(3.3 \mathrm{mmHg}$ and $5.4 \mathrm{mmHg}$ higher 
respectively) [35]. This may be mediated by salt intake as soft drink consumers (including diet drinks) tend to have diets higher in salt [35]. Alternatively, given the cross-sectional nature of this study, it is possible that participants with high BP changed to diet drinks in attempt to make healthier choices. Our study did not measure salt consumption in these adolescents hence we were unable to investigate this, but it is noted the sugar sweetened beverage consumption was low in this sample (less than one per day on average).

Similarly, our study did not identify any meaningful relationship between plant protein and BP as opposed to evidence from the INTERMAP study [36] and the PREMIER trial [24]. This may be due to the different type and quality of plant protein consumed two decades ago $[24,36]$. Our study included ultra-processed plant-based alternatives that are relatively new to the market and which were not analysed in both prior studies. Hence, this makes direct comparisons between the studies difficult due to the dissimilar nutritional components from varying plant protein sources.

Being overweight is a well-established independent risk factor for the development of hypertension [9,10,37-39] and this is consistent with our findings. However, to our knowledge, no studies have specifically explored how weight status moderates associations between dietary intake and hypertension in adolescents. In this research, we noticed that even though meat, vegetable, and milk consumption were similar among adolescents of different weight status, the relationship between these food groups and high BP was dependent on the overweight status of the participants. In particular, vegetable and milk intake were related to decreased odds of hypertension while meat intake was related to increased odds of hypertension among overweight participants and these relationships were not observed in normal weight participants. With overweight adolescents already at increased odds of hypertension, these results indicated that higher vegetable and milk intake with lower meat intake could further decrease their likelihood of developing hypertension.

The major strength of this study is that we utilised both dietary habits questionnaire data and multiple-pass 24-h diet recalls, to estimate usual dietary intake. Moreover, all interviewers were trained to follow a strict protocol to minimise measurement error, thus improving accuracy. Furthermore, with accurate measurements of BMI, we were able to assess the moderating effects of weight status. This enabled us to disentangle the relationship between the diet and body adiposity to determine if diet can modify the risk of hypertension over and above body weight, though it should be noted that our sample consisted of multiple ethnicities where the appropriateness of overweight definitions may vary. There were several limitations in our study. Firstly, our data collection was interrupted due to COVID-19 lockdown and therefore a smaller sample size was recruited than hoped for. However, with 100 participants, regression models with several predictor variables can still be reliably estimated [40], although the exploratory moderating analyses should be interpreted with caution. Secondly, sampling bias may be present as we did not utilise a random sample. Thus, the sample does not represent the general NZ male adolescent population. Thirdly, we could not adjust for well-established confounding factors for high BP such as salt intake and physical activity levels [9] because we did not undertake 24-h urinary sodium tests and our measures of physical activity (through accelerometry) were limited to only a few participants due to COVID-19 restrictions. Lastly, BP was only measured in a single day as opposed to the standardised multiple days [41].

\section{Conclusions}

Our findings indicated that fruit, vegetable, and milk intake were associated with lower BP in a sample of male adolescents. In overweight adolescents, vegetable and milk intake appeared protective against hypertension, but meat intake was related to increased odds of hypertension. These were not observed in normal weight participants, demonstrating that certain dietary factors may have more prominent effects on BP among overweight individuals. Future research should aim to explore and validate how these dietary factors interact; through large scale longitudinal studies and trials while considering potential confounders such as salt intake and physical activity levels. 
Author Contributions: Conceptualization, J.Y., M.C.P., and J.J.H.; methodology, M.C.P., E.A.F., and K.W.; formal analysis, J.Y. and J.J.H.; data curation, J.J.H., E.A.F., and K.W.; writing-original draft preparation, J.Y.; writing-review and editing, J.Y. and J.J.H.; supervision, M.C.P. and J.J.H.; project administration, T.S. and H.M.N. All authors have read and agreed to the published version of the manuscript.

Funding: This research was funded by the Department of Human Nutrition, University of Otago.

Institutional Review Board Statement: The study was approved by the Human Research Ethics Committee at the University of Otago, reference number H20/004), and was registered under the Australian New Zealand Clinical Trials Registry, reference number ACTRN12620000185965.

Informed Consent Statement: Informed consent was obtained from all subjects involved in the study.

Data Availability Statement: The data presented in this study are available on request from the corresponding author.

Acknowledgments: The authors would like to thank all the participating high schools and the SuNDiAL research team that facilitated this study.

Conflicts of Interest: The authors declare no conflict of interest. The funders had no role in the design of the study; in the collection, analyses, or interpretation of data; in the writing of the manuscript, or in the decision to publish the results.

\section{Appendix A}

Table A1. Differences in demographics and habits by age group and weight status.

\begin{tabular}{|c|c|c|c|c|c|c|}
\hline & \multicolumn{2}{|c|}{ Age Group } & \multicolumn{4}{|c|}{ Weight Status } \\
\hline & $\begin{array}{c}15 \text { to }<17 \text { Years } \\
(n=66)\end{array}$ & $\begin{array}{c}17 \text { to }<18 \text { Years } \\
(n=31)\end{array}$ & $p$-Value ${ }^{\text {a }}$ & $\begin{array}{c}\text { Not Overweight } \\
\quad(n=64)\end{array}$ & Overweight $(n=33)$ & $p$-Value ${ }^{a}$ \\
\hline Age, years & $16.2(0.5)$ & $17.5(0.3)$ & - & $16.6(0.8)$ & $16.7(0.6)$ & 0.541 \\
\hline Age group, $n(\%)$ & & & - & & & 0.502 \\
\hline 15 to $<17$ years & $66(100)$ & 0 & & $45(68.2)$ & $21(31.8)$ & \\
\hline 17 to $<18$ years & 0 & $31(100)$ & & $19(61.3)$ & $12(38.7)$ & \\
\hline Deprivation, $n(\%)$ & & & 0.961 & & & 0.003 \\
\hline Low & $22(66.7)$ & $11(33.3)$ & & $25(75.8)$ & $8(24.2)$ & \\
\hline Medium & $30(69.8))$ & $13(30.2)$ & & $32(74.4)$ & $11(24.6)$ & \\
\hline High & $14(66.7)$ & $7(33.3)$ & & $7(33.3)$ & $14(66.7)$ & \\
\hline Ethnicity, $n(\%)$ & & & 0.406 & & & 0.350 \\
\hline NZEO & $36(64.3)$ & $20(35.7)$ & & $36(64.3)$ & $20(35.7)$ & \\
\hline Māori & $6(60.0)$ & $4(40.0)$ & & $5(50.0)$ & $5(50.0)$ & \\
\hline Asian & $24(77.4)$ & $7(22.6)$ & & $23(74.2)$ & $8(25.8)$ & \\
\hline BMI $z$-score, mean (SD) & $0.36(1.10)$ & $0.60(1.20)$ & 0.323 & $-0.21(0.70)$ & $1.69(0.64)$ & - \\
\hline Weight status, $n(\%)$ & & & 0.502 & & & - \\
\hline Not overweight & $45(70.3)$ & $19(29.7)$ & & $64(100)$ & 0 & \\
\hline Overweight & $21(63.6)$ & $12(36.4)$ & & 0 & $33(100)$ & \\
\hline \multicolumn{7}{|l|}{$\begin{array}{l}\text { Dietary habits }{ }^{\mathrm{b}} \text {, mean (SD) } \\
\text { serves per day }\end{array}$} \\
\hline Fruit & $1.4(1.1)$ & $1.5(1.1)$ & 0.816 & $1.3(1.0)$ & $1.6(1.2)$ & 0.371 \\
\hline Vegetables & $1.5(1.1)$ & $1.8(1.2)$ & 0.173 & $1.5(1.1)$ & $1.8(1.4)$ & 0.174 \\
\hline Milk & $1.2(1.0)$ & $1.5(1.3)$ & 0.233 & $1.2(1.1)$ & $1.5(1.1)$ & 0.121 \\
\hline Meat & $2.0(1.2)$ & $2.5(1.2)$ & 0.052 & $2.1(1.3)$ & $2.3(1.0)$ & 0.461 \\
\hline Plant protein ${ }^{c}$ & $1.4(1.3)$ & $1.5(1.4)$ & 0.849 & $1.5(1.2)$ & $1.4(1.5)$ & 0.712 \\
\hline Sweet drinks ${ }^{d}$ & $1.0(1.4)$ & $1.2(2.0)$ & 0.648 & $1.0(1.3)$ & $1.2(2.1)$ & 0.615 \\
\hline Snacks ${ }^{\mathrm{e}}$ & $2.1(2.0)$ & $1.8(1.4)$ & 0.400 & $2.0(1.7)$ & $1.9(2.1)$ & 0.656 \\
\hline Daily dietary intake ${ }^{f}$ & $N=56$ & $N=32$ & & $N=58$ & $N=30$ & \\
\hline Energy, MJ & $10.4(4.0)$ & $11.3(3.7)$ & 0.274 & $10.1(2.7)$ & $11.8(5.5)$ & 0.055 \\
\hline Protein, $\%$ energy & $18.0(3.4)$ & $18.7(2.7)$ & 0.311 & $18.3(3.1)$ & $18.3(3.3)$ & 0.976 \\
\hline Fat, \% energy & $37.9(6.6)$ & $37.0(4.9)$ & 0.505 & $37.3(6.3)$ & $38.0(5.6)$ & 0.630 \\
\hline Carbohydrate, \% energy & $46.0(7.2)$ & $45.0(6.1)$ & 0.519 & $46.2(6.5)$ & $44.5(7.4)$ & 0.272 \\
\hline Fibre, $\mathrm{g}$ & $24.3(9.9)$ & $28.4(12.9)$ & 0.105 & $25.2(9.8)$ & $27.0(13.7)$ & 0.476 \\
\hline
\end{tabular}

a $p$-value calculated with a t-test for continuous variables or a Fisher's exact test for categorical variables; ${ }^{\mathrm{b}}$ Dietary habits assessed using the dietary habits questionnaire and measures frequency of intake; ${ }^{c}$ Plant protein includes legumes, chickpeas, kidney beans, baked beans, tofu, tempeh, tofu products, vegetarian ingredients (such as Quorn, nut meat, vegetarian mince), vegetarian sausages, nuggets, patties, vegetarian "meat alternatives" (such as chicken-free chicken, vegetarian chicken schnitzel, meat-free bacon rashers); ${ }^{\mathrm{d}}$ Sweet drinks includes "diet" drinks but excludes alcoholic beverages (sensitivity analysis showed a significantly lower odds for each non-diet drink extra per day: adjusted odds ratio (95\% CI); $0.85(0.72,1.00), p=0.049) ;{ }^{\text {e }}$ Snacks includes lollies, sweets, chocolate, confectionary, biscuits, cakes, muffins, sweet pastries, muesli or nut bars, and savoury snacks such as crisps and crackers; ${ }^{\mathrm{f}} \mathrm{MJ}$ : Megajoules; Dietary intake assessed using 24 -h recalls, adjusted for usual intake. 


\section{References}

1. $\quad$ Bennett, J.E.; Stevens, G.A.; Mathers, C.D.; Bonita, R.; Rehm, J.; Kruk, M.E.; Riley, L.M.; Dain, K.; Kengne, A.P.; Chalkidou, K.; et al. NCD Countdown 2030: Worldwide trends in non-communicable disease mortality and progress towards Sustainable Development Goal target 3.4. Lancet 2018, 392, 1072-1088. [CrossRef]

2. Abbafati, C.; Machado, D.B.; Cislaghi, B. Global burden of 87 risk factors in 204 countries and territories, 1990-2019: A systematic analysis for the Global Burden of Disease Study 2019. Lancet 2020, 396, 1223-1249.

3. Ministry of Health. Tier 1 statistics 2018/19: New Zealand Health Survey; Ministry of Health: Wellington, New Zealand, 2019.

4. American Heart Association. Know Your Risk Factors for High Blood Pressurel American Heart Association; American Heart Association: Dallas, TX, USA, 2017; pp. 1-3.

5. Aparicio-Cercós, C.; Alacreu, M.; Salar, L.; Royo, L.M. Waist-to-height ratio and skipping breakfast are predictive factors for high blood pressure in adolescents. Sci. Rep. 2020, 10, 16704. [CrossRef] [PubMed]

6. Kolahdooz, F.; Nader, F.; Jang, S.L.; Daemi, M.; Ezekowitz, J.A.; Johnston, N.; Cruickshank, K.; Sharma, S. Elevated Blood Pressure and Associations with Sodium Intake Among Multiethnic Youth in Edmonton, Canada: Findings from WHY ACT NOW. High. Blood Press Cardiovasc. Prev. 2020, 27, 239-249. [CrossRef]

7. Al Kibria, G.M.; Swasey, K.; Sharmeen, A.; Day, B. Estimated change in prevalence and trends of childhood blood pressure levels in the United States after application of the 2017 AAP guideline. Prev. Chronic Dis. 2019, 16, E12. [CrossRef] [PubMed]

8. Abrignani, M.G.; Lucà, F.; Favilli, S.; Benvenuto, M.; Rao, C.M.; di Fusco, S.A.; Gabrielli, D.; Gulizia, M.M. Lifestyles and Cardiovascular Prevention in Childhood and Adolescence. Pediatr. Cardiol. 2019, 40, 1113-1125. [CrossRef] [PubMed]

9. Frisoli, T.M.; Schmieder, R.E.; Grodzicki, T.; Messerli, F.H. Beyond salt: Lifestyle modifications and blood pressure. Eur. Heart J. 2011, 32, 3081-3087. [CrossRef] [PubMed]

10. Oduwole, A.A.; Ladapo, T.A.; Fajolu, I.B.; Ekure, E.N.; Adeniyi, O.F. Obesity and elevated blood pressure among adolescents in Lagos, Nigeria: A cross-sectional study. BMC Public Health 2012, 12, 616. [CrossRef]

11. Leong, K.S.W.; Jayasinghe, T.N.; Wilson, B.C.; Derraik, J.G.B.; Albert, B.B.; Chiavaroli, V.; Svirskis, D.M.; Beck, K.L.; Conlon, C.A.; Jiang, Y.; et al. High prevalence of undiagnosed comorbidities among adolescents with obesity. Sci. Rep. 2020, $10,20101$. [CrossRef]

12. Atkinson, J.; Salmond, C.; Crampton, P. NZDep2018 Index of Deprivation Interim Research Report; University of Otago: Wellington, New Zealand, 2019; Volume 5541, pp. 1-65.

13. Ministry of Health. HISO 10001:2017 Ethnicity Data Protocols; Ministry of Health: Wellington, New Zealand, 2017.

14. Ministry of Health. A Portrait of Health. Key Results pf the 2006/07 New Zealand Health Survey; Ministry of Health: Wellington, New Zealand, 2008.

15. Gibson, S.R.; Ferguson, L.E. An Interactive 24-Hours Recall for Assessing the Adequacy of Iron and Zinc Intakes in Developing Countries; HarvestPlus Technical Monograph 8; ILSI Press: Washington, DC, USA, 2008; Volume 10.

16. Harttig, U.; Haubrock, J.; Knüppel, S.; Boeing, H. The MSM program: Web-based statistics package for estimating usual dietary intake using the Multiple Source Method. Eur. J. Clin. Nutr. 2011, 65, S87-S91. [CrossRef]

17. Public Health Intelligence. Protocol for Collecting Height, Weight and Waist Measurements in New Zealand Health Monitor (NZHM) Surveys; Ministry of Health: Wellington, New Zealand, 2008; pp. 1-7.

18. de Onis, M.; Onyango, A.W.; Borghi, E.; Siyam, A.; Nishida, C.; Siekmann, J. Development of a WHO growth reference for school-aged children and adolescents. Bull. World Health Organ. 2007, 85, 660-665. [CrossRef]

19. Fan, H.; Liu, Y.; Zhang, X. Validation of recommended definition in identifying elevated blood pressure in adolescents. J. Clin. Hypertens. 2019, 21, 1343-1349. [CrossRef]

20. Amrhein, V.; Trafimow, D.; Greenland, S. Inferential Statistics as Descriptive Statistics: There Is No Replication Crisis if We Don't Expect Replication. Am. Stat. 2019, 73 (Suppl. 1), 262-270. [CrossRef]

21. Greenland, S.; Senn, S.J.; Rothman, K.J.; Carlin, J.B.; Poole, C.; Goodman, S.N.; Altman, D.G. Statistical tests, P values, confidence intervals, and power: A guide to misinterpretations. Eur. J. Epidemiol. 2016, 31, 337-350. [CrossRef]

22. Damasceno, M.M.C.; De Araújo, M.F.M.; Freire de Freitas, R.W.J.; de Almeida, P.C.; Zanetti, M.L. The association between blood pressure in adolescents and the consumption of fruits, vegetables and fruit juice-An exploratory study. J. Clin. Nurs. 2011, 20, 1553-1560. [CrossRef]

23. Yang, Y.; Dong, B.; Zou, Z.; Wang, S.; Dong, Y.; Wang, Z.; Ma, J. Association between vegetable consumption and blood pressure, stratified by BMI.; among Chinese adolescents aged 13-17 years: A national cross-sectional study. Nutrients 2018, 10, 451. [CrossRef]

24. Wang, Y.F.; Yancy, W.S.; Yu, D.; Champagne, C.; Appel, L.J.; Lin, P.H. The relationship between dietary protein intake and blood pressure: Results from the PREMIER study. J. Hum. Hypertens. 2008, 22, 745-754. [CrossRef]

25. Couch, S.C.; Saelens, B.E.; Levin, L.; Dart, K.; Falciglia, G.; Daniels, S.R. The efficacy of a clinc-based behavioral nutrition intervention emphasizing a DASH-type diet for adolescents with elevated blood pressure. J. Paediatr. 2008, 152, 494-501. [CrossRef]

26. Krupp, D.; Shi, L.; Egert, S.; Wudy, S.A.; Remer, T. Prospective relevance of fruit and vegetable consumption and salt intake during adolescence for blood pressure in young adulthood. Eur. J. Nutr. 2015, 54, 1269-1279. [CrossRef] 
27. Tighe, P.; Duthie, G.; Vaughan, N.; Brittenden, J.; Simpson, W.G.; Duthie, S.; Mutch, W.; Wahle, K.; Horgan, G.; Thies, F. Effect of increased consumption of whole-grain foods on blood pressure and other cardiovascular risk markers in healthy middle-aged persons: A randomized controlled trial. Am. J. Clin. Nutr. 2010, 92, 733-740. [CrossRef]

28. He, J.; Streiffer, R.H.; Muntner, P.; Krousel-Wood, M.A.; Whelton, P.K. Effect of dietary fiber intake on blood pressure: A randomised, double-blind, placebo-controlled trial. J. Hypertens. 2004, 22, 73-80. [CrossRef] [PubMed]

29. Chan, Q.; Stamler, J.; Griep, L.M.O.; Daviglus, M.L.; Van Horn, L.; Elliott, P. An Update on Nutrients and Blood Pressure. J. Atheroscler. Thromb. 2016, 23, 276-289. [CrossRef]

30. Hidayat, K.; Du, H.Z.; Yang, J.; Chen, G.C.; Zhang, Z.; Li, Z.N.; Qin, L.Q. Effects of milk proteins on blood pressure: A meta-analysis of randomized control trials. Hypertens. Res. 2017, 40, 264-270. [CrossRef] [PubMed]

31. Elliott, P.; Kesteloot, H.; Appel, L.J.; Dyer, A.R.; Ueshima, H.; Chan, Q.; Brown, I.J.; Zhao, L.; Stamler, J.; INTERMAP Cooperative Research Group. Dietary phosphorus and blood pressure: International study of macro- and micro-nutrients and blood pressure. Hypertension 2008, 51, 669-675. [CrossRef]

32. Chan, T.F.; Lin, W.T.; Huang, H.L.; Lee, C.; Wu, P.; Chiu, Y.; Huang, C.; Tsai, S.; Lin, C.; Lee, C. Consumption of Sugar-sweetened beverages is associated with components of the metabolic syndrome in adolescents. Nutrients 2014, 6, 2088-2103. [CrossRef]

33. Mirmiran, P.; Yuzbashian, E.; Asghari, G.; Hosseinpour-Niazi, S.; Azizi, F. Consumption of sugar sweetened beverage is associated with incidence of metabolic syndrome in Tehranian children and adolescents. Nutr. Metab. 2015, 12, 25. [CrossRef] [PubMed]

34. Nguyen, S.; Choi, H.K.; Lustig, R.H.; Hsu, C.Y. Sugar-Sweetened Beverages, Serum Uric Acid, and Blood Pressure in Adolescents. J. Pediatr. 2009, 154, 807-813. [CrossRef]

35. Souza, B.D.S.N.; Cunha, D.B.; Pereira, R.A.; Sichieri, R. Soft drink consumption, mainly diet ones, is associated with increased blood pressure in adolescents. J. Hypertens. 2016, 34, 221-225. [CrossRef]

36. Elliot, P.; Stamler, J.; Dyer, A.R.; Appel, L.; Dennis, B.K.H. Association Between Protein Intake and Blood Pressure. Arch. Intern. Med. 2006, 166, 79-87. [CrossRef]

37. Hussein Bdair, B.W.; Al-Graittee, S.J.R.; Jabbar, M.S.; Kadhim, Z.H.; Lawal, H.; Alwa'aly, S.H.; Abutiheen AA, K. Cardiovascular risk factors for hypertension and diabetes among overweight and obese adolescents in the city of Kerbala, Iraq. J. Cardiovasc. Dis. Res. 2020, 11, 32-39.

38. Din-Dzietham, R.; Liu, Y.; Bielo, M.V.; Shamsa, F. High blood pressure trends in children and adolescents in national surveys, 1963 to 2002. Circulation 2007, 116, 1488-1496. [CrossRef]

39. Falkner, B. Hypertension in children and adolescents: Epidemiology and natural history. Pediatr. Nephrol. 2010, 25, 1219-1224. [CrossRef]

40. Wilson Van Voorhis, C.R.; Morgan, B.L. Understanding Power and Rules of Thumb for Determining Sample Sizes. Tutor. Quant. Methods Psychol. 2007, 3, 43-50. [CrossRef]

41. Chiolero, A.; Cachat, F.; Burnier, M.; Paccaud, F.; Bovet, P. Prevalence of hypertension in schoolchildren based on repeated measurements and association with overweight. J. Hypertens. 2007, 25, 2209-2217. [CrossRef] [PubMed] 